\title{
In-situ investigation of the microstructure evolution in nanocrystalline copper electrodeposits at room temperature
}

\author{
Pantleon, Karen; Somers, Marcel A. J.
}

Published in:

Journal of Applied Physics

Link to article, DOI:

$10.1063 / 1.2401647$

Publication date:

2006

Document Version

Publisher's PDF, also known as Version of record

Link back to DTU Orbit

Citation $(A P A)$ :

Pantleon, K., \& Somers, M. A. J. (2006). In-situ investigation of the microstructure evolution in nanocrystalline copper electrodeposits at room temperature. Journal of Applied Physics, 100(11), 114319.

https://doi.org/10.1063/1.2401647

\section{General rights}

Copyright and moral rights for the publications made accessible in the public portal are retained by the authors and/or other copyright owners and it is a condition of accessing publications that users recognise and abide by the legal requirements associated with these rights.

- Users may download and print one copy of any publication from the public portal for the purpose of private study or research.

- You may not further distribute the material or use it for any profit-making activity or commercial gain

- You may freely distribute the URL identifying the publication in the public portal

If you believe that this document breaches copyright please contact us providing details, and we will remove access to the work immediately and investigate your claim 


\title{
In situ investigation of the microstructure evolution in nanocrystalline copper electrodeposits at room temperature
}

\author{
Karen Pantleon ${ }^{\text {a) }}$ and Marcel A. J. Somers \\ Department of Manufacturing Engineering and Management, Technical University of Denmark, Kemitorvet, \\ Building 204, DK-2800 Kongens Lyngby, Denmark
}

(Received 24 August 2006; accepted 7 October 2006; published online 12 December 2006)

\begin{abstract}
The microstructure evolution in copper electrodeposits at room temperature (self-annealing) was investigated by means of $\mathrm{x}$-ray diffraction analysis and simultaneous measurements of the electrical resistivity as a function of time. In situ studies were started immediately after deposition of the various thick layers and continued with a unique time resolution until stabilization of the recorded data occurred. Independent of the copper layer thickness, the as-deposited microstructure consisted of nanocrystalline grains with orientation dependent crystallite sizes. Orientation dependent grain growth, crystallographic texture changes by multiple twinning, and a decrease of the electrical resistivity occurred as a function of time at room temperature. The kinetics of self-annealing is strongly affected by the layer thickness: the thinner the layer, the slower the microstructure evolution is, and self-annealing is suppressed completely for a thin layer with $0.4 \mu \mathrm{m}$. The preferred crystallographic orientation of the as-deposited crystallites is suggested to cause the observed thickness dependence of the self-annealing kinetics. (0) 2006 American Institute of Physics.
\end{abstract}

[DOI: $10.1063 / 1.2401647]$

\section{INTRODUCTION}

Copper has been recognized as particularly suitable for interconnects in advanced microelectronic devices. The complicated structure of interconnects, i.e., the arrangement of multiple patterned levels above each other and the tiny feature sizes with dimensions of less than a micrometer require the method of electroplating for the deposition of copper. Electrochemical deposition of copper has a long tradition and many decades ago it was observed that the microstructure of copper changes as a function of time at room temperature. ${ }^{1,2}$ Since the era of copper interconnects this socalled self-annealing effect came into focus. ${ }^{3-5}$ Selfannealing has been recognized as an unwanted side effect in the successful manufacturing of copper thin films for applications in microelectronics and postdeposition annealing at elevated temperatures for stabilizing the microstructure has been introduced as an integrated part of the manufacturing process. Even so self-annealing can be prevented by intentional annealing at elevated temperatures, the phenomenon remains of scientific and technological interest, since understanding the kinetics and mechanisms of self-annealing is the essence of tailoring the microstructure.

There is no doubt that self-annealing has a substantial effect on the microstructure and the associated properties of electrodeposited copper. Experimental observations of decreasing electrical resistivity and hardness, improvements of the ductility, increasing grain size and surface roughness, changes in crystallographic texture, and level of internal stresses as a function of time at room temperature are frequently reported, e.g., Refs. 3 and 5-13. However, discus-

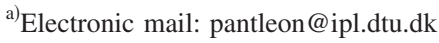

sions on the origin and mechanisms of self-annealing are nonconsistent in literature and understanding of the kinetics of self-annealing is still lacking.

A suitable procedure enabling experimental investigation of the evolution of the microstructure is a prerequisite for studying the self-annealing behavior. This is not straightforward due to the low film thickness and the often fine-grained microstructure of as-deposited films. Furthermore, knowledge on the true as-deposited microstructure is required, which implies that the investigation must start immediately after deposition, and any kind of sample preparation with the risk of modifying the as-deposited microstructure by thermal or mechanical influences must be avoided.

Electrical resistivity measurements as a function of time after deposition have been found to be a suitable straightforward method in order to verify the onset and kinetics of self-annealing. ${ }^{3,13}$ Electrical resistivity is closely related to the microstructure, i.e., it is affected by the grain size, the grain orientation, and grain boundary characteristics, as well as by the density of point and line defects. ${ }^{3,14}$ Due to the multitude of microstructural features simultaneously affecting the electrical resistivity, time dependent changes of the electrical resistivity can hardly be related to individual features of the microstructure and therefore, the actual cause of the microstructure evolution cannot be concluded solely on the basis of the observed resistivity decrease with time.

In order to relate changes of the electrical resistivity to the microstructure, in the present work, x-ray diffraction (XRD) experiments were performed simultaneously with measurement of the electrical resistivity on the same sample. XRD provides information on the microstructure: (i) grain size and lattice defects affect the shape and width of XRD 
line profiles (line profile analysis) and (ii) the diffracted intensities yield the preferred grain orientation (quantitative crystallographic texture analysis).

\section{EXPERIMENT}

\section{A. Electrochemical deposition}

Copper thin films were electrochemically deposited onto [100] oriented $\mathrm{Si}$ wafers covered with a thin evaporated $\mathrm{Ti}-\mathrm{Au}$ double layer acting as plating base. The upper $\mathrm{Au}$ intermediate substrate layer has a strong $\langle 111\rangle$ fiber texture. The acidic based copper electrolyte (commercially available UBAC ${ }^{\mathrm{TM}}$ ER electrolyte) contained leveling and brightening additives. The bath was operated under the commercially recommended conditions: the electrolyte temperature was $28^{\circ} \mathrm{C}$, vigorous air agitation, and continuous filtration was applied. Deposition was carried out with a cathode current density of $4 \mathrm{~A} / \mathrm{dm}^{2}$ and a current thief was placed around the cathode to improve the distribution of copper on the wafer substrate. The deposition time was varied such that various film thicknesses from less than $1 \mu \mathrm{m}$ up to a thickness of a few micrometers were obtained. The deposited wafers were cleaned in water and in situ studies of self-annealing were started immediately after deposition; a minimum of $4 \mathrm{~min}$ was required for cleaning, drying, and mounting the sample in the experimental setup.

\section{B. Measurement procedure}

The coated wafers were mounted in an x-ray diffractometer Discover D8, Bruker AXS, and at the same time electrical resistivity measurements with a Tinsley Micro Ohmmeter 5891 were started on the same wafer. The electrical resistivity was recorded with $1 \mathrm{~min}$ intervals. Simultaneously, XRD line profiles of the 111 and 200 Bragg reflections (with scattering vector perpendicular to the surface) were measured repeatedly until the line profiles approached the instrumental broadening, which was determined from a standard Si powder (NIST 640c), i.e., further changes of the microstructure as derived from line profile analysis (crystallite size and microstrain) could not be detected any longer. Thereafter, crystallographic texture analysis was performed at different times up to a total self-annealing time of about $1 \mathrm{yr}$ after deposition. The crystallographic texture was quantified by calculating the orientation distribution function ${ }^{15}$ (ODF) from 111, 200, and 311 pole figures, which were measured applying sample rotations around the surface normal (azimuth angle $\varphi, 0 \leqslant \varphi \leqslant 360^{\circ}$, step size $5^{\circ}$ ) and sample tilts (pole angle $\psi, 0 \leqslant \psi \leqslant 75^{\circ}$, step size $5^{\circ}$ ) and corrected for background and defocusing. The ODF was calculated with LABOTEX (LaboSoft Krakow, Poland).

\section{RESULTS AND INTERPRETATION OF THE RESULTS}

\section{A. Electrical resistivity}

The evolution of the electrical resistivity of wafers covered with $\mathrm{Cu}$ layers of various thicknesses is presented in Fig. 1. In the continuous decrease of the electrical resistivity various stages can be distinguished. Within the first ca.

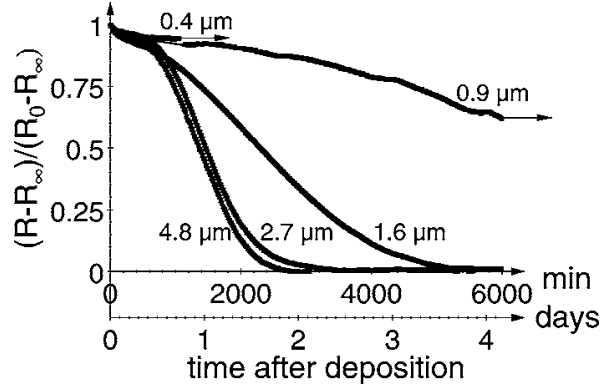

FIG. 1. Electrical resistivity $R$ as a function of time after deposition of $\mathrm{Cu}$ films with different thicknesses $\left(R_{0}\right.$-initial value; $R_{\infty}$-stable value at room temperature). The arrows indicate that resistivity did not stabilize for the low film thicknesses (there, $R_{\infty}$ was taken assuming a total decrease of $16 \%$ as observed for all other samples).

100 min, the resistivity drops by about $4 \%$, independent of the film thickness. Then, the electrical resistivity decreases at a lower rate until a steeper drop of the resistivity occurs and it finally stabilizes at room temperature. A total resistivity decrease of about $16 \%$ was observed before the stabilization occurred at room temperature for the $\mathrm{Cu}$ layers thicker than $1 \mu \mathrm{m}$. The time scale of the recorded changes depends on the film thickness; ${ }^{16}$ the thinner the film, the longer it takes before a drastic resistivity change commences and stabilization occurs. For the $\mathrm{Cu}$ layers thinner than $1 \mu \mathrm{m}$, no stabilization was obtained within the first 4 days (cf. Fig. 1). Further measurements revealed that for the $0.9 \mu \mathrm{m}$ thick sample the electrical resistivity continued to decrease slowly, one month after deposition a total resistivity change of only 5.8\% was determined and the electrical resistivity has not stabilized yet.

\section{B. XRD line profile analysis}

XRD line profile analysis also indicates the onset of selfannealing: strong changes of the line profiles were observed. A few selected line profiles for a copper layer with $2.7 \mu \mathrm{m}$ thickness are shown in Fig. 2; considerable changes of the linewidths and diffracted intensities are clearly visible.

The measured line profiles were fitted with a superposition of two pseudo-Voigt functions (corresponding to the $K \alpha_{1}$ and the $K \alpha_{2}$ components) and yielded the position, width, and shape, as well as the integrated intensity of the individual lines. In the following, only the parameters corresponding to the $K \alpha_{1}$ component are reported and related to the microstructure of the $\mathrm{Cu}$ layers. Figure 3 shows the time dependence of the linewidths [in terms of full widths at half maximum (FWHM)] and the ratio of integrated intensities for the 111 and 200 diffraction lines as obtained from the pseudo-Voigt fit for the various $\mathrm{Cu}$ layers with different thicknesses. For comparison, an integrated intensity ratio of 111 and 200 line profiles $I_{\text {int }}-111 / I_{\text {int }}-200=2.35$ was measured for a textureless standard powder sample. Rather weak intensities measured for the 200 diffraction lines of the thinnest samples caused scattering of the corresponding data obtained from the pseudo-Voigt fit and hence for these samples trend lines are given rather than the measured data and marked by the dash dotted curves in Figs. 3(b) and 3(c). 

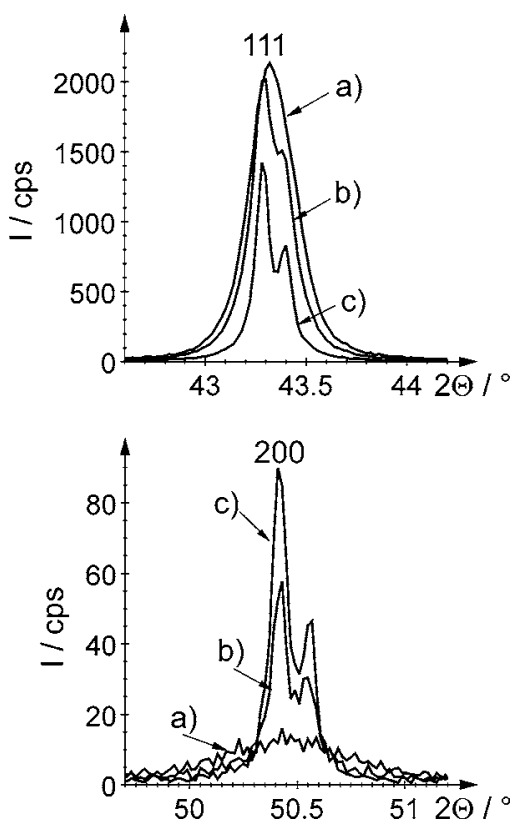

FIG. 2. Selected XRD line profiles as measured for the 111 and 200 lattice

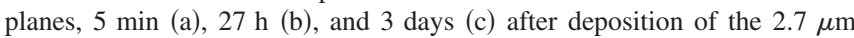
thick $\mathrm{Cu}$ layer. Note, the $K \alpha_{2}$ component is not stripped in the graphs.

In order to relate the measured line profiles to the microstructure, the single line approach ${ }^{17,18}$ for separating the influences of the size of coherently diffracting domains and lattice microstrain on the broadening of diffraction lines was applied. Line profile fitting with a pseudo-Voigt function,
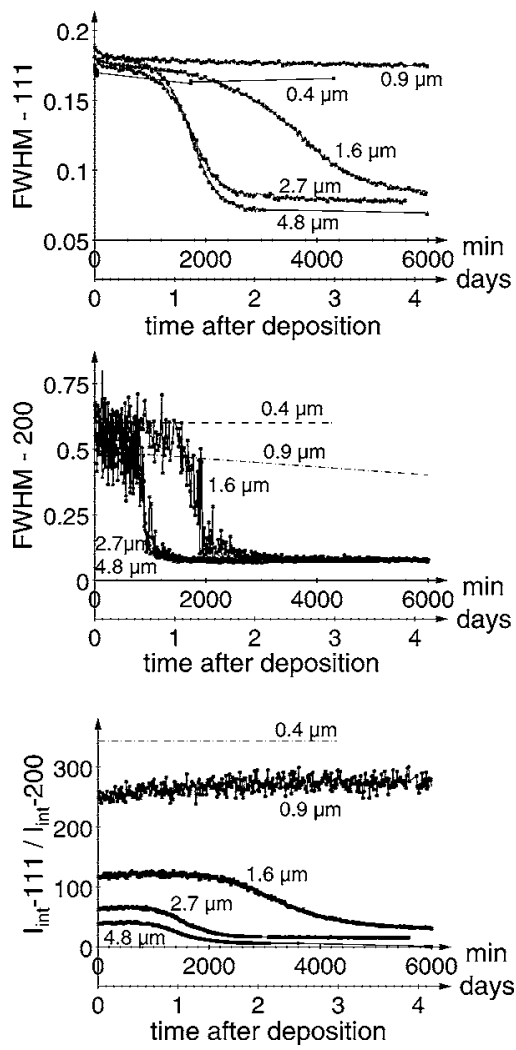

FIG. 3. Linewidth (FWHM) and integrated intensity ratio $\left(I_{\text {int }}-111 / I_{\text {int }}\right.$ -200) of 111 and 200 line profiles of $K \alpha_{1}$ as function of time after deposition of $\mathrm{Cu}$ layers with different thicknesses.

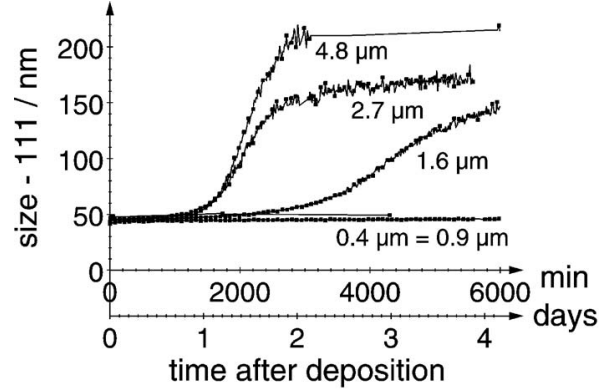

(a)

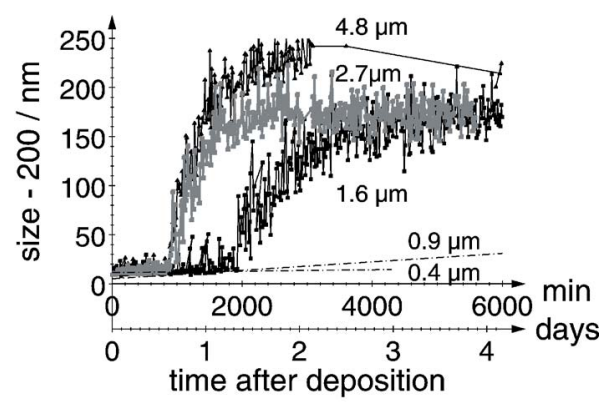

(b)

FIG. 4. Crystallite size calculated from the broadening of 111 (a) and 200 (b) diffraction lines.

i.e., a superposition of a Lorentz and a Gauss function, revealed that all recorded XRD line profiles were purely Lorentzian in shape. It is well accepted that Lorentzian broadening of XRD line profiles is related to the size of the coherently diffracting domains, ${ }^{18,19}$ which can be considered to be the size of grains or subgrains, ${ }^{20}$ i.e., the crystallite size. From the integral breadth $\beta_{L}$, which was obtained from the FWHM and corrected for instrumental broadening, the crystallite size $D$ was calculated according to ${ }^{17,18}$

$$
D=\frac{\lambda}{\beta_{L} \cos \Theta} .
$$

The evolution of the crystallite size as obtained from the single line method applied on the 111 and 200 diffraction lines, respectively, is shown in Fig. 4. It should be noted that conventional x-ray diffraction as applied here is not useful to determine grain sizes larger than, say, $200 \mathrm{~nm}$ and hence it cannot be concluded whether a stable grain size has actually been reached and what the final stable grain size is.

The following results can be summarized from Figs. 2-4. In the as-deposited state, the line profiles of 111 and 200 diffraction lines are quite different: grains with 111 lattice planes parallel to the surface yield huge intensities, but much smaller linewidths compared to those obtained for the grains with 200 planes parallel to the surface, which gave broad lines with very weak intensities. The as-deposited crystallite sizes amount to about $50 \mathrm{~nm}$ for $\langle 111\rangle$ oriented grains and about $15 \mathrm{~nm}$ for grains with $\langle 100\rangle$ orientation. While the linewidths (and correspondingly the crystallite size) of the as-deposited state is almost independent on the thickness of the $\mathrm{Cu}$ layers, the integrated intensities indicate a clear thickness dependence. With increasing film thickness, the ratio of the integrated intensities of 111 and 200 diffract- 
TABLE I. Time period after deposition until $50 \%$ of the total change of the electrical resistivity $(R)$, XRD line widths (FWHM), and integrated intensity $\left(I_{\text {int }}\right)$ occurred.

\begin{tabular}{|c|c|c|c|c|c|}
\hline \multirow[b]{2}{*}{$\begin{array}{c}\mathrm{Cu} \text { thickness } \\
(\mu \mathrm{m})\end{array}$} & \multirow[b]{2}{*}{$\begin{array}{c}\Delta R(50 \%) \\
\quad(\mathrm{h})\end{array}$} & \multicolumn{2}{|c|}{$\Delta$ FWHM $(50 \%)$} & \multicolumn{2}{|c|}{$\Delta I_{\text {int }}(50 \%)$} \\
\hline & & $\begin{array}{l}111 \\
(\mathrm{~h})\end{array}$ & $\begin{array}{l}200 \\
\text { (h) }\end{array}$ & $\begin{array}{l}111 \\
\text { (h) }\end{array}$ & $\begin{array}{l}200 \\
(\mathrm{~h})\end{array}$ \\
\hline 0.4 & $\infty$ & $\infty$ & $\infty$ & $\infty$ & $\infty$ \\
\hline 0.9 & $333^{\mathrm{a}}$ & 631.0 & 160.0 & 637.0 & 572.0 \\
\hline 1.6 & 38 & 60.0 & 31.0 & 60.0 & 55.0 \\
\hline 2.7 & 24 & 29.0 & 14.0 & 30.5 & 26.0 \\
\hline 4.8 & 22 & 28.5 & 14.0 & 31.5 & 29.0 \\
\hline
\end{tabular}

${ }^{\mathrm{a}}$ Estimated value (from curve fitting) since resistivity measurement of the $0.9 \mu \mathrm{m}$ thick layer was not continued until $50 \%$ of the total expected change was reached.

ing lattice planes decreases, since with increasing thickness much weaker 111 intensities were measured for the asdeposited layers. Consequently, in the as-deposited microstructure the volume fraction of $\langle 111\rangle$ oriented grains is much larger than the volume fraction of $\langle 100\rangle$ oriented grains as the ratio $I_{\text {int }}-111 / I_{\text {int }}-200$ is above 2.35 (the value of a textureless sample), and the thinner the $\mathrm{Cu}$ layers the higher the $\langle 111\rangle$ volume fraction is.

It is observed that the kinetics of self-annealing depends both on the size and/or orientation of the as-deposited crystallites as well as the thickness of the Cu layers. With respect to the layer thickness, the same observation as for the evolution of the electrical resistivity (see above) is made: the thinner the films, the later self-annealing begins and the $\mathrm{Cu}$ layers with thicknesses less than $1 \mu \mathrm{m}$ remained almost stable within the reported period of several days (cf. Fig. 3). For the thinner layers, further XRD analysis was carried out at several times for a total period of more than $1 \mathrm{yr}$ after deposition. These measurements revealed that the microstructure of the $0.9 \mu \mathrm{m}$ thick layer stabilizes about 4 months after deposition, while the $0.4 \mu \mathrm{m}$ thick layer still was in the as-deposited state even $1 \mathrm{yr}$ after deposition (neither changes of the widths nor the intensities of the profiles were observed), i.e., no self-annealing occurred for such a thin $\mathrm{Cu}$ layer.

For comparison, the time periods corresponding to $50 \%$ of the total change of the recorded data are summarized in Table I for the various $\mathrm{Cu}$ layers.

\section{Crystallographic texture analysis}

After stabilization of the electrical resistivity and the diffraction linewidth was observed for the three thicker samples after a certain time, quantitative crystallographic texture analyses were carried out. It was found that the crystallographic textures of the self-annealed samples consist of multiple fiber components with a $\langle 111\rangle$ fiber texture as the main component. ${ }^{16}$ On the basis of the evolution of the integrated intensities of the diffraction lines [cf. Fig. 3(c)], it was suggested that the crystallographic texture changes as a function of time. This behavior is confirmed also by thorough texture analysis repeated on the $0.9 \mu \mathrm{m}$ thick $\mathrm{Cu}$ layer over the period of about almost $1 \mathrm{yr}$, which indeed revealed that the

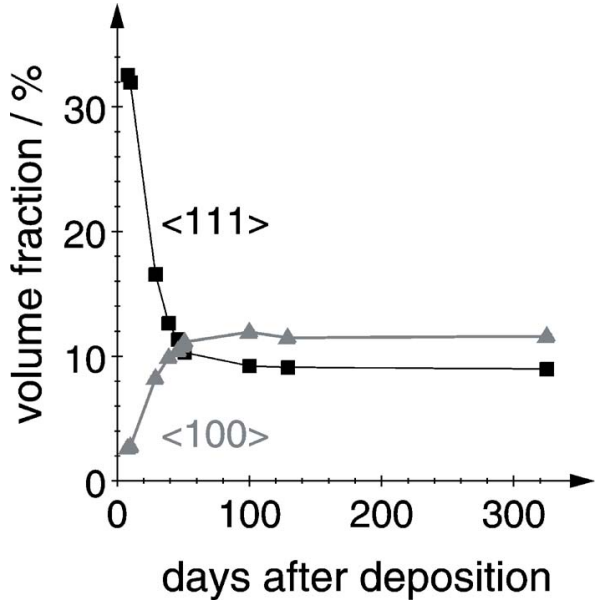

FIG. 5. Volume fraction of the $\langle 111\rangle$ and $\langle 100\rangle$ fiber textures (allowing for a deviation of up to $10^{\circ}$ from the fiber axes) as a function of time for the $0.9 \mu \mathrm{m}$ thick $\mathrm{Cu}$ layer.

volume fraction of the $\langle 111\rangle$ component decreases drastically with time, as shown in Fig. 5. For the $0.9 \mu \mathrm{m}$ thick Cu layer, the decreasing volume fraction of the $\langle 111\rangle$ fiber texture was accompanied by the development of a $\langle 100\rangle$ fiber texture component, which became stronger with time (cf. Fig. 5).

Figure 6 gives an overview of the crystallographic texture for all samples as measured about $1 \mathrm{yr}$ after the deposition of the $\mathrm{Cu}$ layers. The inverse pole figures indicate the occurrence frequencies of crystal directions in a specific sample direction; ${ }^{15}$ since fiber textures were observed here, inverse pole figures in normal direction, i.e., perpendicular to the surface, are sufficient for a complete quantitative description of the texture. It is expected that the results presented in Fig. 6 represent the final stable crystallographic texture at room temperature.

A $\langle 111\rangle$ fiber texture was observed for all samples and the $\langle 111\rangle$ fiber texture is more pronounced the thinner the self-annealed $\mathrm{Cu}$ layer is. ${ }^{16}$ Additionally, various minor texture components were identified, which overlap and form broad regions of enhanced orientation density. ${ }^{16}$ As indicated in Fig. 6(f), the additional texture components fall within two regions: region I covers components ranging from $\langle 100\rangle$ to $\langle 411\rangle$, and region II lies in the center of the inverse pole figure and ranges from $\langle 11.5 .4\rangle$ to $\langle 221\rangle$ and includes $\langle 321\rangle$. Our recent conclusion ${ }^{16}$ that the formation of the various minor texture components is a consequence of selfannealing, since these texture components can be related to multiple twinning, ${ }^{16}$ is corroborated by the present observation. The minor texture components are not present for the thinnest layer with $0.4 \mu \mathrm{m}$ (cf. Fig. 6(a)), where no sign of self-annealing was observed.

For comparison, Fig. 7(a) shows the integrated intensity ratio of the 111 and 200 diffraction lines for the as-deposited state and for the same sample after storage for $1 \mathrm{yr}$ at room temperature. The volume fraction of the $\langle 111\rangle$ fiber texture component measured $1 \mathrm{yr}$ after deposition is given in Fig. 7(b).

Figure 7 again confirms that within 1 yr after deposition no self-annealing occurred for the thinnest $\mathrm{Cu}$ layer with $0.4 \mu \mathrm{m}$, i.e., the as-deposited microstructure consisting of a 


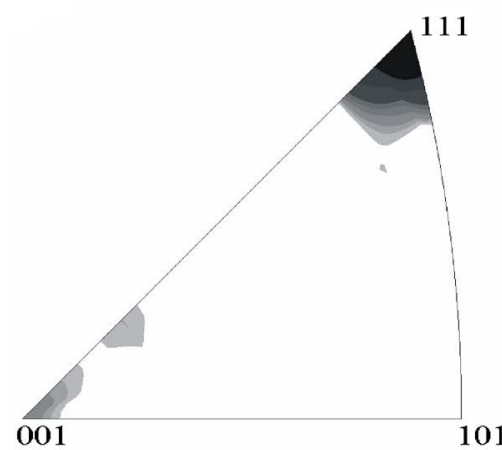

a) $d=0.4 \mu m$

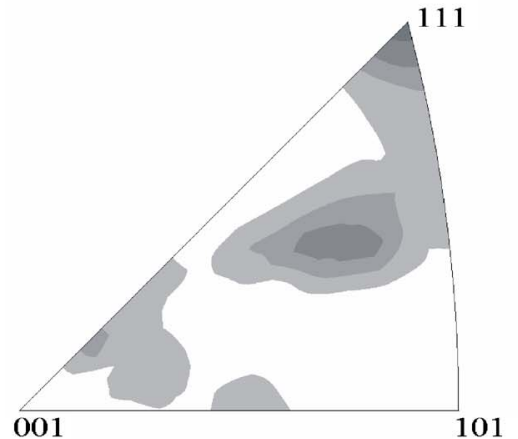

d) $d=2.7 \mu m$

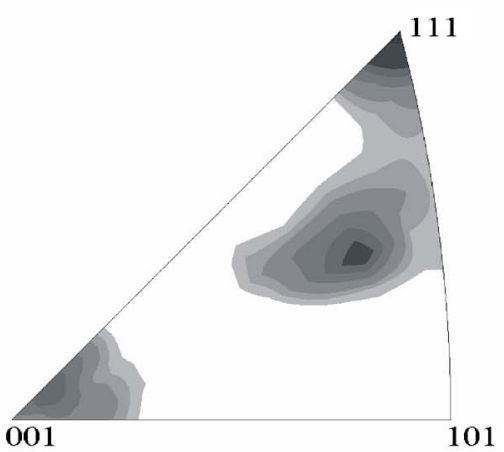

b) $d=0.9 \mu \mathrm{m}$

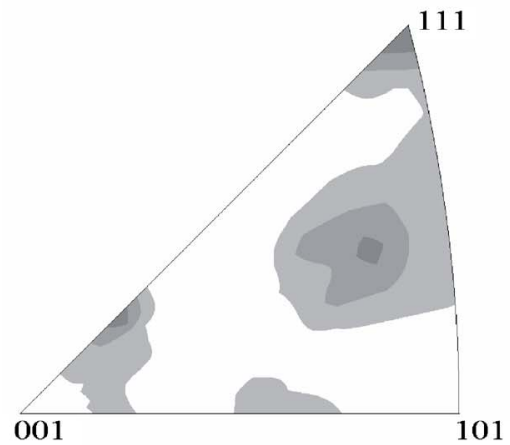

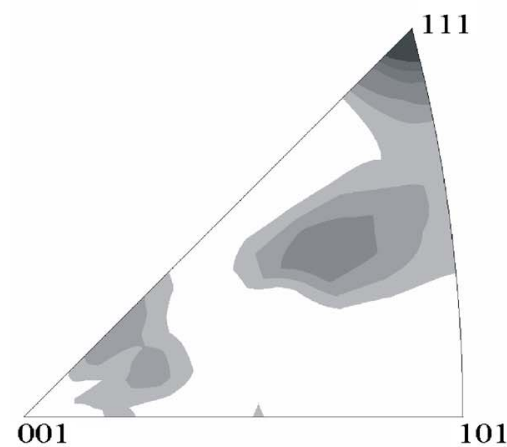

c) $d=1.6 \mu \mathrm{m}$

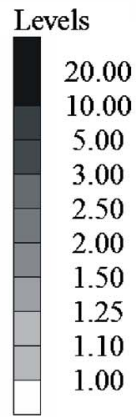

e) $d=4.8 \mu \mathrm{m}$

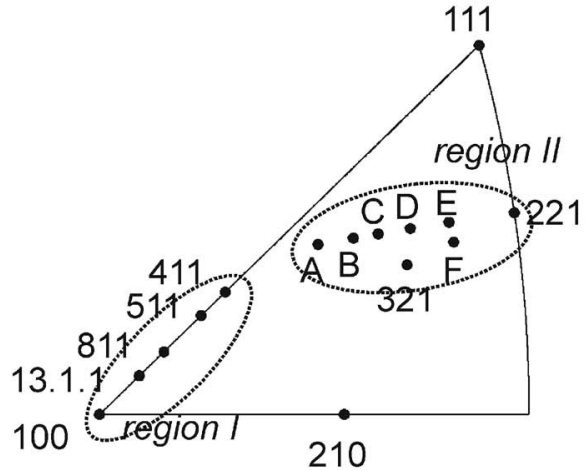

$$
\begin{aligned}
& A=11.5 .4 \\
& B=13.7 .5 \\
& C=532 \\
& D=19.13 .8 \\
& E=29.23 .13 \\
& F=542
\end{aligned}
$$

\section{f) texture components}

FIG. 6. Inverse pole figures in normal direction measured $1 \mathrm{yr}$ after deposition of the Cu layers with different thicknesses [(a)-(e)]. A schematic drawing for identifying the individual texture components is given (f).

very strong $\langle 111\rangle$ fiber texture remained stable at room temperature. In contrast, self-annealing occurred for the thicker layers as indicated by the decreased intensity ratio within 1 yr compared to the as-deposited state [cf. Fig. 7(a)]. Correspondingly, a decreasing volume fraction of $\langle 111\rangle$ oriented crystallites with time is proposed (and proven, cf. Fig. 5), causing the final stable microstructure to consist of a much lower fraction of $\langle 111\rangle$ oriented grains, which slightly depends on the layer thickness [cf. Fig. 7(b)].

\section{DISCUSSION}

\section{A. The as-deposited microstructure}

The most obvious feature of the as-deposited microstructure is the orientation dependent crystallite size. Independent of the layer thickness, the $\langle 111\rangle$ oriented crystallites have an average size of about $50 \mathrm{~nm}$, while crystallites with $\langle 100\rangle$ orientation are considerably smaller with about $15 \mathrm{~nm}$ crystallite sizes on average.

The observation of orientation dependent crystallite sizes and, in particular, the presence of larger crystallite sizes for those crystallites constituting the preferred crystallographic orientation can be discussed as follows. First, it should be emphasized that a possibly larger inaccuracy in the determination of the size of $\langle 100\rangle$ oriented crystallites because of the initially lower intensity of the 200 diffraction lines and truncation of the long-tail contributions ${ }^{21}$ to these broad line profiles cannot explain the observation (on the contrary, the hook effect, i.e., an overestimation of the diffraction background level, would result in even smaller values for the $\langle 100\rangle$ crystallite sizes). 


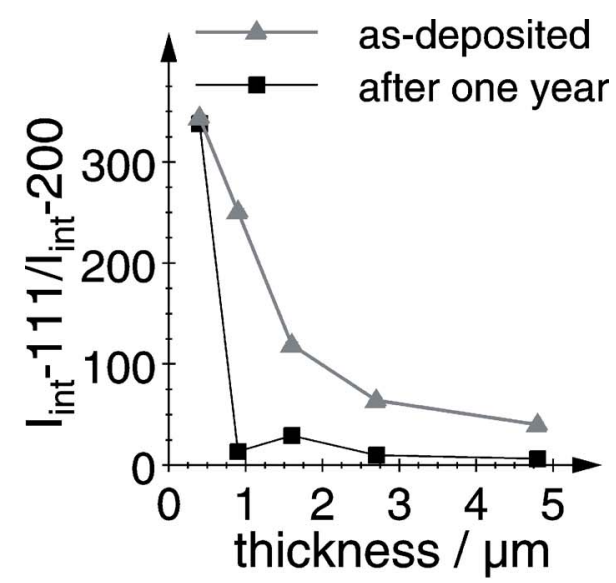

(a)

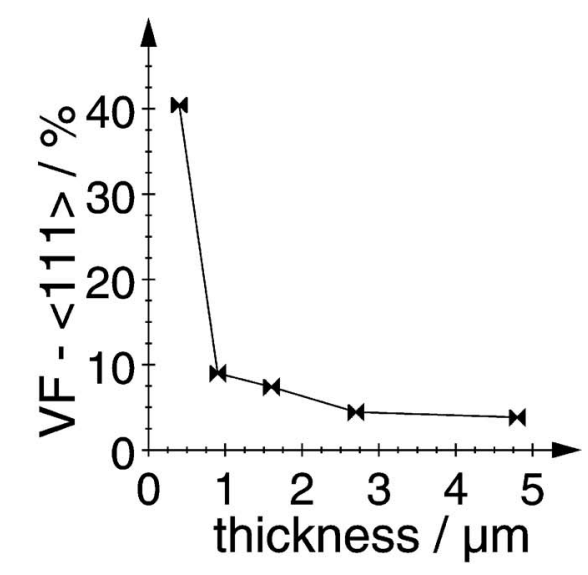

(b)

FIG. 7. Effect of the layer thickness on the crystallographic texture: (a) ratio of the integrated intensity of 111 and 200 diffraction lines as deposited and about $1 \mathrm{yr}$ after deposition, and (b) volume fraction of the $\langle 111\rangle$ fiber texture (allowing for a deviation of up to $10^{\circ}$ from the fiber axis) about $1 \mathrm{yr}$ after deposition.

The volume fraction of as-deposited $\langle 111\rangle$ oriented crystallites strongly depends on the $\mathrm{Cu}$ layer thickness; it decreases with increasing thickness. Although the present results indicate this for various samples with different layer thicknesses, a similar thickness dependence can be expected to occur also within one and the same layer in dependence on the distance to surface. Such an enormously increased fraction of preferred $\langle 111\rangle$ orientation at the interface can be explained by rotational epitaxy between crystallites in the $\mathrm{Cu}$ layer adjacent to the strongly $\langle 111\rangle$ oriented $\mathrm{Au}$ substrate intermediate layer, ${ }^{22}$ yielding a decreasing volume fraction of the $\langle 111\rangle$ oriented crystallites with increasing $\mathrm{Cu}$ layer thickness as observed here. Due to rotational epitaxy, nucleation of $\langle 111\rangle$ oriented crystallites is fairly easy, since nucleation is assisted by the substrate intermediate layer and therefore nuclei with $\langle 111\rangle$ orientation become larger than those with $\langle 100\rangle$ (and other) orientation(s), which nucleate unassisted. It should be emphasized that the as-deposited crystallite sizes and their orientation dependence is found to be independent of the layer thickness. This indicates that the decrease of the $\langle 111\rangle$ volume fraction with increasing layer thickness is caused by a reduced number of $\langle 111\rangle$ oriented grains in direction to the surface and not by smaller grains. An orienta- tion dependence of the as-deposited grain size has also been reported recently for thick $\mathrm{Cu}$ films, ${ }^{23}$ but usually, orientation averaged grain sizes are reported in literature.

\section{B. Kinetics of self-annealing}

The results presented above indicate that the thickness of the $\mathrm{Cu}$ layers considerably affects the kinetics of selfannealing: the thinner the $\mathrm{Cu}$ layer, the slower the kinetics of microstructure changes at room temperature, whereby selfannealing is completely suppressed for a layer thickness of $0.4 \mu \mathrm{m}$ only. A similar thickness dependence of the selfannealing kinetics has been observed previously. ${ }^{6,7,24-27}$ Supported by the observation of even slower kinetics observed for $\mathrm{Cu}$ deposited in damascene trenches, ${ }^{8,28,29}$ the thickness dependence has been attributed to geometrical constraints due to trench and via structures and/or the interface and surface of the film. ${ }^{8}$ This, however, does not explain the complete absence of self-annealing in the thinnest $\mathrm{Cu}$ layer, as observed in the present study, since the as-deposited crystallite sizes are considerably smaller than the layer thickness.

In the present study, the only obvious difference in the as-deposited state of the various $\mathrm{Cu}$ layers with different thicknesses is their initial preferred crystallographic orientation. While the orientation dependence and average size of the as-deposited crystallites is not influenced by the layer thickness, the strength of the as-deposited $\langle 111\rangle$ texture clearly is; the preferred formation of grains with $\langle 111\rangle$ orientation is more pronounced the thinner the $\mathrm{Cu}$ layers are. ${ }^{16,22}$ The slowest kinetics was observed for the thinnest layer, i.e., the one with the strongest $\langle 111\rangle$ fiber texture. In a strongly $\langle 111\rangle$ oriented film, most of the grains, i.e., the $\langle 111\rangle$ oriented grains, are surrounded by other $\langle 111\rangle$ grains and hence lowangle grain boundaries, which are known to be rather immobile. In contrast, the high mobility of the high-angle grain boundaries of $\langle 100\rangle$ oriented grains embedded in a matrix of grains with $\langle 111\rangle$ orientation may cause relatively rapid growth of the $\langle 100\rangle$ oriented grains at the expense of the $\langle 111\rangle$ grains. The larger the volume fraction of $\langle 111\rangle$ oriented grains, the more likely is the dominance of low-angle grain boundaries and hence the slower is the kinetics of selfannealing. For the very thin $\mathrm{Cu}$ layers with a very strong $\langle 111\rangle$ single fiber texture, a scarcity of the mobile high-angle boundaries exists and hence self-annealing is prevented. This confirms that an epitaxial orientation relation (which is considered to provoke the $\langle 111\rangle$ texture of the present samples ${ }^{22}$ ) or in general a strong texture retards the onset and the course of self-annealing as proposed earlier. ${ }^{16}$

It has been reported ${ }^{4,26}$ that nucleation of new grains occurs at the surface and growth then proceeds inwards. In combination with the observed texture differences, this further could explain the faster kinetics of thicker films. The thicker the film, the weaker is the $\langle 111\rangle$ texture at the surface and hence the easier self-annealing occurs.

The nanocrystallinity of the as-deposited $\mathrm{Cu}$ layers suggests that the grain boundary energy is the driving force $\mathrm{j}^{3,13}$ for the microstructure evolution during self-annealing. Grain growth in the classical sense, i.e., curvature driven grain growth with isotropic grain boundary energies and 
mobilities ${ }^{30}$ implies that larger grains grow at the expense of smaller grains. The present results show that, additionally to the orientation dependence of the as-deposited crystallite size, also the growth rate of the grains depends on their orientation. It is observed that the smaller $\langle 100\rangle$ oriented grains grow first and faster than the $\langle 111\rangle$ oriented grains, and shortly after they started growing, the $\langle 100\rangle$ oriented crystallites become even larger than the $\langle 111\rangle$ ones; this occurs the sooner the $\mathrm{Cu}$ layer becomes thicker. Such an orientation dependent growth can be explained by orientation dependent grain boundary energies and mobilities. ${ }^{31}$ Effects of anisotropic grain boundary energies have been suggested recently for electrodeposited $\mathrm{Cu}$ films. ${ }^{32}$

Often, the process of self-annealing in $\mathrm{Cu}$ electrodeposits is assumed to be similar to the high temperature annealing of highly deformed $\mathrm{Cu}$ bulk material (although the driving forces in both cases are certainly different). Indeed, similar changes of microstructure and properties are found in the experiments, and accordingly, self-annealing might be interpreted in terms of recovery, recrystallization, and grain growth. ${ }^{33}$ The present results indeed indicate the occurrence of various stages of the microstructure evolution. The initial stability of the integrated intensities of the diffraction lines [cf. Fig. 3(c)] reflects an unchanged crystallographic texture. This implies that recrystallization, which would be accompanied by dramatic texture changes, did not occur initially. During the incubation time for the onset of recrystallization and grain growth, the microstructure is not stable, as indicated by the slightly decreasing electrical resistivity and the related decreasing diffraction linewidth. This may reflect the process of recovery. At a later stage, the sudden and strong decrease of the electrical resistivity accompanied by strong changes of the XRD line profiles (with respect to both the linewidths and the integrated intensities) and changes of the volume fraction of preferred crystallographic orientations indicate the transformation of the microstructure by recrystallization and/or grain growth.

A detailed quantification and interpretation of selfannealing in terms of recovery, recrystallization, and grain growth applying the Johnson-Mehl-Avrami-Kolmogorov approach $^{33}$ will be given elsewhere.

\section{CONCLUSIONS}

In situ studies of self-annealing in nanocrystalline copper electrodeposits were carried out by measuring electrical resistivity simultaneously to $\mathrm{x}$-ray diffraction analysis on one and the same samples with a unique time resolution ranging from immediately after deposition over about $1 \mathrm{yr}$. The results indicate the following.

(a) The as-deposited state consists of nanocrystalline grains with orientation dependent crystallite sizes $(\langle 100\rangle$ crystallites: about $15 \mathrm{~nm},\langle 111\rangle$ crystallites: about $50 \mathrm{~nm}$ ), but the $\mathrm{Cu}$ layer thickness does not affect the as-deposited crystallite sizes.

(b) The overall kinetics of self-annealing become faster the thicker the copper layer and self-annealing did not occur for a $\mathrm{Cu}$ layer with $0.4 \mu \mathrm{m}$ thickness only.

(c) The kinetics depends on the size and/or orientation of grains: slower kinetics was found for the as-deposited $\langle 111\rangle$ oriented grains despite the fact that they are larger (noncurvature driven grain growth).

(d) The as-deposited texture is suggested to cause the observed thickness dependence of the self-annealing kinetics (epitaxy retards self-annealing by inducing many low-angle grain boundaries).

(e) Self-annealing occurs in various stages.

\section{ACKNOWLEDGMENTS}

The authors are grateful to the Danish Research Council for Technology and Production Sciences (FTP Grant No. 2603-0276) for financial support to the present work.

${ }^{1}$ M. Cook and T. Richards, J. Inst. Met. 70, 159 (1944).

${ }^{2}$ H. Binder and H. Fischer, Z. Metallkd. 53, 161 (1962).

${ }^{3}$ J. M. E. Harper, C. Cabral, Jr., P. C. Andricacos, L. Gignac, I. C. Noyen, K. P. Rodbell, and C. K. Hu, J. Appl. Phys. 86, 2516 (1999).

${ }^{4}$ C. Lingk and M. E. Gross, J. Appl. Phys. 84, 5547 (1998).

${ }^{5}$ S. Lagrange, S. H. Brongersma, M. Judelewicz, A. Saerens, I. Vervoort, E. Richard, R. Palmans, and K. Maex, Microelectron. Eng. 50, 449 (2000).

${ }^{6}$ W. H. Teh, L. T. Koh, S. M. Chen, J. Xie, C. Y. Li, and P. D. Foo, Microelectron. J. 32, 579 (2001).

${ }^{7}$ Q.-T. Jiang, R. Mikkola, and B. Carpenter, Conference Proceedings ULSI XIV (Materials Research Society, 1999), pp. 177-181.

${ }^{8}$ Q.-T. Jiang, M. E. Thomas, G. Bersuker, B. Foran, R. Mikkola, B. Carpenter, and J. Ormando, Mater. Res. Soc. Symp. Proc. 564, 429 (1999).

${ }^{9}$ D. N. Buckley and S. Ahmed, Electrochem. Solid-State Lett. 6, C33 (2003).

${ }^{10}$ M. Hasegawa, Y. Nonaka, Y. Negishi, Y. Okinaka, and T. Osaka, J. Electrochem. Soc. 153, C117 (2006).

${ }^{11}$ M. Stangl, J. Acker, V. Ditel, W. Gruner, V. Hoffmann, and K. Wetzig, Microelectron. Eng. 82, 189 (2005).

${ }^{12}$ H. Lee, W. D. Nix, and S. S. Wong, J. Vac. Sci. Technol. B 22, 2369 (2004).

${ }^{13}$ M. Militzer, P. Freundlich, and D. Bizzotto, Mater. Sci. Forum 467-470, 1339 (2004).

${ }^{14}$ I. Nakamichi, J. Sci. Hiroshima Univ., Ser. A: Phys. Chem. 54, 49 (1990).

${ }^{15}$ H.-J. Bunge, Texturae Analysis in Materials Science: Mathematical Method (Cuvillier, Göttingen, 1993).

${ }^{16}$ K. Pantleon and M. A. J. Somers, Scr. Mater. 55, 283 (2006).

${ }^{17}$ J. I. Langford, J. Appl. Crystallogr. 11, 10 (1978).

${ }^{18}$ T. H. de Keijser, J. I. Langford, E. J. Mittemeijer, and A. B. P. Vogels, J. Appl. Crystallogr. 15, 308 (1982).

${ }^{19}$ Z. Zhang, F. Zhou, and E. J. Lavernia, Metall. Mater. Trans. A 34A, 1349 (2003).

${ }^{20}$ T. Ungar, Adv. Eng. Mater. 5, 323 (2003).

${ }^{21}$ A. C. Vermeulen, R. Delhez, T. H. de Kejser, and E. J. Mittemeijer, J. Appl. Phys. 71, 5303 (1992).

${ }^{22}$ K. Pantleon and M. A. J. Somers, Acta Mater. 52, 4929 (2004).

${ }^{23}$ L. Lu, N. R. Tao, L. B. Wang, B. Z. Ding, and K. Lu, J. Appl. Phys. 89, 6408 (2001).

${ }^{24}$ D. Walther, M. E. Gross, K. Evans-Lutterodt, W. L. Brown, M. Oh, S. Merchant, and P. Naresh, Mater. Res. Soc. Symp. Proc. 612, G711D1011 (2000).

${ }^{25}$ S. H. Brongersma, E. Richard, I. Vervoort, and K. Maex, Proceedings of the Interconnect Technology Conference (Electronic Devices Society Press, 2000), pp. 31-33.

${ }^{26}$ S. H. Brongersma, E. Richard, I. Vervoort, H. Bender, W. Vandervorst, S. Lagrange, G. Beyer, and K. Maex, J. Appl. Phys. 86, 3642 (1999).

${ }^{27}$ R. Rosenberg, D. C. Edelstein, C.-K. Hu, and K. P. Rodbell, Annu. Rev. Mater. Sci. 30, 229 (2000).

${ }^{28}$ M. E. Gross et al., Mater. Res. Soc. Symp. Proc. 562, 215 (1999).

${ }^{29}$ S. H. Brongersma, J. D'Haen, K. Vanstreels, W. DeCeuninck, I. Vervoort, and K. Maex, Mater. Sci. Forum 426-432, 2485 (2003).

${ }^{30}$ M. Hillert, Acta Metall. 13, 227 (1965).

${ }^{31}$ G. Abbruzzese and K. Lücke, Acta Metall. 34, 905 (1986).

${ }^{32}$ J.-M. Paik, Y.-J. Park, M.-S. Yon, J.-H. Lee, and Y.-C. Joo, Scr. Mater. 48, 683 (2003).

${ }^{33}$ F. J. Humphreys and M. Hatherly, Recrystallization and Related Annealing Phenomena (Pergamon, New York, 1996). 